\title{
EduQNet: Um Modelo de Qualidade de Processo para Cursos a Distância Mediados pela Internet
}

\author{
Francisco J. C. Rapchan ${ }^{1,2,3}$ \\ Davidson Cury ${ }^{1}$ \\ Crediné Menezes ${ }^{1}$ \\ Ricardo de Almeida Falbo ${ }^{1}$ \\ ${ }^{1}$ Mestrado em Informática - UFES \\ Av. Fernando Ferrari s/nº , Vitória - ES. CEP 29060-900 \\ \{rapchan; dede; credine; falbo\}@inf.ufes.br \\ ${ }^{2}$ UNESC - Centro Universitário do Espírito Santo. \\ R. Talma Rodrigues Ribeiro, 41, Serra - ES. CEP 29173-495 \\ chicorapchan@hotmail.com \\ ${ }^{3}$ FAVI - Associação Vitoriana de Ensino Superior \\ Av. Nossa Senhora da Penha, 1800, Vitória - ES. CEP 29045-400 \\ chicorapchan@hotmail.com
}

\begin{abstract}
Resumo
Este artigo propõe um modelo de qualidade de processo para a elaboração, operação, gerência e manutenção de cursos a distância que utilizem a Internet como elemento mediador. O modelo proposto toma como base a norma NBR ISO/IEC 12207 para fazer um mapeamento dos processos sugeridos a partir de indicadores de qualidade propostos por diversas instituições relacionadas com educação a distância.

Palavras-chave: qualidade de processo, educação a distância, modelo de EAD; projeto de cursos a distância.
\end{abstract}

\begin{abstract}
This paper suggests a process quality model to elaborate, operate, manage, and maintain distant learning mediated by Internet. The model is based on NBR ISO/IEC 12207 and on a merge of processes suggested by different organizations dealing with e-learning.

Keywords: process quality, distance education, e-learning, distance education model, e-learning design.
\end{abstract}

\section{Introdução}

A globalização das relações humanas, permitida pelo encurtamento das distâncias através da tecnologia, tem modificado a percepção da importância do conhecimento na sociedade moderna. A combinação da enorme demanda educacional, associada à facilidade de acesso a recursos tecnológicos vem favorecendo o crescimento do número de cursos através da modalidade de educação a distância mediados pela Internet. Este crescimento em número, entretanto, nem sempre vem acompanhado de um equivalente crescimento em qualidade.

O objetivo deste trabalho é propor um modelo de qualidade de processo para a elaboração, operação, gerência e manutenção de cursos a distância que utilizem a Internet 
como elemento mediador. O modelo proposto toma como base a norma NBR ISO/IEC 12207 [12] para um mapeamento dos processos a partir de indicadores de qualidade propostos por instituições relacionadas com educação a distância no Brasil e em outros países.

Este modelo, denominado de EduQNet (Educação com Qualidade Mediada pela Internet), deverá servir como proposta inicial para cursos a distância oferecidos pelo Núcleo de Educação Aberta e a Distância da Ufes - NE@AD [17,18].

\section{EAD e a Qualidade de Processo}

A EAD - Educação a Distância - é uma área de grande interesse na atualidade, embora não seja nova. Suas origens remontam os cursos por correspondência criados a partir do desenvolvimento do serviço postal regular. Esses programas continuaram se desenvolvendo e foram aperfeiçoados no século XX, com o surgimento de novos meios de transmissão da informação como o rádio e a televisão.

É possível identificar ao longo do tempo quatro gerações de tecnologias de EAD [23]. A primeira geração foi desenvolvida a partir de 1840 e é baseada no texto escrito através do serviço postal. A geração seguinte, surge na década de 1950 utilizando a televisão e o rádio. A terceira geração incorpora as tecnologias das duas primeiras gerações, produzindo um sistema de multimídia. A quarta geração aparece no final dos anos 1990, a partir do desenvolvendo de sistemas de comunicação mediados pelo computador, como as conferências assistidas por computador e o correio eletrônico. Nesta geração são criadas as primeiras universidades virtuais.

Várias instituições, autores e pesquisadores têm se esforçado, ao longo dos anos, para elaborar definições precisas e completas a respeito de EAD. Em Nunes [19] e em Belloni [2] encontramos uma lista dessas definições de EAD apresentadas ao longo das últimas décadas. A maioria destas definições é descritiva e define EAD de forma muito tendenciosa, a partir da perspectiva do ensino convencional da sala de aula. O parâmetro comum a todas elas é a distância, entendida em termos de espaço. A separação entre professores e alunos no tempo não é explicitada, embora esta talvez seja mais importante no processo de ensino e aprendizagem a distância do que a "não-contiguidade espacial".

Independentemente da definição adotada, deve-se entender que a EAD tem sua identidade própria e os cursos não podem ser oferecidos nesta nova modalidade simplesmente adaptando os conteúdos dos cursos presenciais. É necessário repensar todo o processo de ensino redesenhando conteúdos, abordagens didáticas e planos pedagógicos para a nova mídia. Kawasaki [13] lembra que a introdução dos ambientes telemáticos na educação deve ser acompanhada de uma evolução correspondente na forma de ensinar/aprender, ou seja, uma correspondente evolução das teorias pedagógicas. Segundo Campos [3], a maioria dos programas de instrução auxiliada pelo computador ainda seguem o paradigma educacional tradicional onde o aluno lê o conteúdo, o seu conhecimento é testado e, se errar, o processo se repete, senão gera nova lição.

Outro problema comum é transferir para a tecnologia expectativas ilusórias. Nas palavras de Preti [23]: "No imaginário de muitas pessoas, um curso via televisão, via satélite ou por computador, num ambiente multimídia ou via Internet, é a garantia da qualidade e da atualidade daquele curso. O texto escrito [impresso] é considerado tecnologia ultrapassada. $O$ curso que se utiliza desta tecnologia é considerado não atrativo e não vendável. Ao se 
elaborar um curso, muitas vezes, pensa-se primeiramente nas tecnologias a serem utilizadas do que propriamente no seu conteúdo, nos seus objetivos, nos sujeitos a serem atendidos. ."

Embora seja comum os países estabelecerem estruturas para a regulamentação das atividades educacionais desenvolvidas por instituições em seu território, essas estruturas não têm sido muito eficazes quando tratam da regulamentação no ambiente internacional e certamente, menos ainda no ambiente cibernético [10]. Assim como em outras áreas do conhecimento humano, o sucesso da EAD está diretamente relacionado à qualidade do processo usado para desenvolvê-lo.

Várias instituições de educação a distância tais como United Kingdon Open University, Indira Gandhi National Open University na Índia e a Open University of Hong Kong têm procurado definir, adaptar e adotar indicadores e modelos para a garantia da qualidade [10]. Esses modelos visam garantir a qualidade dos principais processos envolvidos em educação tais como: planejamento do programa, projeto do curso, desenvolvimento do curso, distribuição do curso e avaliação e promoção do aluno e suporte tecnológico.

\subsection{Um modelo baseado no CMM}

William F. Massy sugere o uso experimental do CMM - Capablility Maturity Model, para avaliar a penetração do trabalho de qualidade educacional nas instituições de ensino a distância, que ele chama de EQW - Education Quality Work [15]. Para Massy esse uso seria em dois níveis: nos departamentos e na instituição como um todo. O modelo para o nível departamental possui 4 níveis (de 0 ao 3), representados da seguinte forma:

Nível 0 Sem Esforço. Este nível é o ponto inicial das tarefas de qualidade em um departamento. $\mathrm{O}$ departamento ainda não tem um programa de qualidade;

Nível 1 Esforços informais. Um número significativo de professores começa a ter experiência com o trabalho de qualidade. Esses professores trabalham individualmente e usam métodos ad hoc, mas suas experiências com os princípios de EQW começaram a produzir feedback positivo dos alunos e colegas. Iniciativas individuais.

Nível 2 Esforço Organizacional. Qualidade como trabalho em grupo ao invés de iniciativas individuais. Iniciativas planejadas e acompanhadas por grupos de trabalho. Métodos baseados em princípios ao invés de ad hoc. Desenvolvimento de métricas para medir a qualidade do trabalho e normas para o que precisar ser feito.

Nível 3 Esforço Maduro. EQW enraizado na cultura. A parte central da cultura acadêmica do departamento é desenvolver EQW. Os professores fazem melhorias contínuas em seus trabalhos e compartilham seus conhecimentos com os outros.

O modelo para a instituição de ensino como um todo possui 6 níveis (de 0 ao 5), representados da seguinte forma:

Nível 0 Sem performance. Não há nenhum EQW. Os métodos tradicionais dominam a universidade.

Nível I Experiências ad hoc e de apagar incêndios. Poucos departamentos começaram a ter experiência com os princípios de EQW e estariam no Nível 1 mas seus esforços 
ainda não atraíram muita atenção ou suporte. Muitas iniciativas de trabalhos em qualidade têm a ver com problemas do ambiente acadêmico e que precisam ser resolvidos imediatamente.

Nível II Programas Emergentes. Alguns departamentos estão no Nível 2 do Modelo de Maturidade Departamental mas a maioria está no nível 1. Há um escritório de promoção da qualidade educacional iniciando sua assistência em qualidade para a universidade. EQW está começando a ser visível por toda a instituição e está sendo discutida pelas faculdades e pela universidade.

Nível III Listar e acompanhar programas. Praticamente todos os departamentos alcançaram o Nível 1, vários estão no Nível 2 e alguns já têm chegado ao Nível 3. EQW tem se transformado no principal objetivo da universidade. Os comitês de qualidade têm acompanhado os progressos dos departamentos e estão preparados para começar a divulgar as práticas exemplares pela universidade.

Nível IV Área dos principais resultados. EQW se tornou a principal área para a universidade e para muitos departamentos. A universidade institucionalizou o acompanhamento de EQW e incluiu os progressos dos departamentos como um critério de performance para verbas.

Nível V Melhoria contínua. EQW se tornou um elemento central da cultura acadêmica da universidade e melhoria contínua da educação tem alcançado paridade com a pesquisa. Participação em trabalhos sobre a qualidade tem se tornado um critério importante de promoção no plano de cargos e salários.

Massy sugere também alguns princípios de boas práticas que devem ser observados em trabalhos sobre qualidade na educação tais como: definir a qualidade da educação em termos de seus efeitos ou resultados; foco no processo de ensino/aprendizagem; trabalho colaborativo no processo curricular e educacional; fazer da melhoria contínua da qualidade uma prioridade.

\subsection{O guia de qualidade do C-RAC}

No ano acadêmico 1996-97, 1.680 instituições nos Estados Unidos estavam oferecendo cursos de graduação a distância com aproximadamente 1,6 milhões de estudantes matriculados [7]. Segundo Hope [10], esta demanda tem fomentado um enorme esforço por parte das comissões regionais de regulamentação do ensino superior americano, para desenvolver guias de programas ensino a distância mediados pela Internet. Este esforço mútuo começou pela criação de um consórcio para a elaboração de padrões de ensino a distância pela Internet gerido por um conselho de educação que representa oito comissões regionais de regulamentação da educação superior americana, o C-RAC - Council of Regional Accrediting Commissions.

Como trabalho preliminar, o conselho propôs alguns documentos para serem avaliados pelos seus membros. Dentre estes documentos os mais importantes são: Statement of the Regional Accrediting Commissions on the Evaluation of Electronically Offered Degree and Certificate Programs e o Guidelines for the Evaluation of Electronically Offered Degree and Certificate Programs [27, 28].

A acreditação (accreditation) é um processo de verificação da qualidade usado para classificar instituições de ensino superior (faculdades, universidades). Esta prática surgiu nos 
Estados Unidos com as agências privadas de educação. Estas agências são organizações privadas, independentes e sem fins lucrativos, constituídas exclusivamente para esse fim e reconhecidas pelo departamento federal de educação USDE - United States Department of Education e pelo Conselho de Acreditação Superior, CHEA - Council for Higher Education Accreditation [7].

O guia proposto pelo C-RAC é composto por vinte e nove parágrafos, cada um descrevendo um aspecto essencial de um programa de educação a distância. Esses parágrafos são agrupados em cinco componentes independentes, cada um relacionado a uma área ou atividade específica da educação a distância. Os cinco componentes são: Comprometimento e contexto institucional; Instrução e currículo; Suporte para a faculdade; Suporte ao aluno; Avaliação (do estudante e do processo de aprendizagem).

Uma característica interessante desse documento é a preocupação estar dirigida ao aluno e ao processo de aprendizagem ao invés da tecnologia ou da burocracia [28]: "Os métodos mudam mas os padrões de qualidade são duradouros. $O$ importante não são os aspectos técnicos mas os direcionamentos curriculares e pedagógicos."

\subsection{O guia de qualidade da HRDC}

O governo Canadense, através do HRDC - Human Resources Development Canada, tem procurado desenvolver projetos que buscam definir padrões de qualidade para EAD [10]. Para isso foi desenvolvido um guia de qualidade para aprendizagem a distância assistida pela tecnologia [1].

O guia estabelece uma série de princípios fundamentais para cursos a distância assistido pela tecnologia. Esses princípios são agrupados em três objetivos principais que são os indicadores da garantia de qualidade: i) Indicadores da garantia de qualidade dos objetivos; ii) Indicadores da garantia de qualidade dos processos e práticas; iii) Indicadores da garantia de qualidade entradas e recursos.

\subsection{Os indicadores de qualidade do MEC/SED}

O Ministério da Educação, através da Secretaria de Educação a Distância sugerem alguns indicadores de qualidade de cursos de graduação a distância através do documento "Indicadores de Qualidade da Educação a Distância" [16]. A proposta é que este documento possa orientar instituições e alunos que desejem cursar uma graduação a distância.

Embora os indicadores sugeridos não tenham ainda força de lei, servirão para orientar as Instituições e as Comissões de Especialistas que forem analisar projetos de cursos de graduação a distância. São dez os itens básicos:

1. Integração com políticas, diretrizes e padrões de qualidade definidos para o ensino superior como um todo e para o curso específico.

2. Desenho do projeto: a identidade da educação a distância.

3. Equipe profissional multidisciplinar.

4. Comunicação e interatividade entre professor e aluno.

5. Qualidade dos recursos educacionais.

6. Infra-estrutura de apoio. 
7. Avaliação de qualidade contínua e abrangente.

8. Convênios e parcerias.

9. Edital e informações sobre o cursos de graduação a distância.

10. Custos de implementação e manutenção da graduação a distância.

\subsection{As referências de qualidade do IHEP}

Em Abril de 2000, o IHEP-Institute for Higher Education Policy lançou um estudo onde identifica os padrões de referência considerados essenciais para garantir a excelência da qualidade em cursos superiores a distância mediado pela Internet $[10,22]$. O estudo foi dividido em três fases. Na primeira, foram identificados na literatura quais eram os principais padrões de qualidade de ensino a distância mediado pela Internet, usados por instituições de ensino, governos, grupos organizados, etc. Essa pesquisa resultou em um total de 45 itens de qualidade recomendados.

$\mathrm{Na}$ fase seguinte, foram identificadas e selecionadas instituições que têm experiência substancial em educação a distância e que oferecem cursos mediados pela Internet. A escolha das instituições levou em consideração entre outros aspectos: (i) O tempo de experiência da instituição com ensino a distância e, em especial, mediado pela Internet; (ii) Seu nível de reconhecimento regional e nacional; (iii) Oferecerem mais de um programa de graduação e pós-graduação a distância pela Internet.

$\mathrm{Na}$ terceira fase, essas instituições foram visitadas para verificar o grau de aderência dessas instituições aos 45 itens de qualidade obtidos na fase inicial. A análise dos dados obtidos nesta fase levou o instituto a concluir que 13 dos padrões identificados inicialmente não eram considerados importantes e que muitos outros poderiam ser combinados. Além disso, foi notada a necessidade de criar 3 novos padrões. Ao final foram identificados 24 padrões de referência considerados essenciais para garantir a excelência em aprendizagem a distância mediada pela Internet. Esses 24 padrões foram agrupados em 7 categorias:

1. Suporte Institucional. Os padrões dessa categoria incluem atividades para garantir um ambiente adequado para a qualidade da educação a distância bem como as políticas que orientam o desenvolvimento do ensino pela Internet. Esses padrões relacionam aspectos como: infra-estrutura técnica, planos de tecnologia, e incentivos profissionais.

2. Desenvolvimento do curso. Esta categoria inclui itens relativos ao desenvolvimento do curso pela Internet (incluindo análise, planejamento, implementação, testes, avaliação, manutenção, etc.).

3. Processo de Tecnologia e Aprendizado. Relaciona as atividades de pedagogia e didática.

4. Estrutura do Curso. Definem as políticas e procedimentos que fornecem suporte ao processo de tecnologia e aprendizado e incluem definição dos objetivos do curso, disponibilidade de recursos bibliográficos, tipos de materiais disponíveis para estudantes, tempo de resposta aos estudantes e avaliação das expectativas dos estudantes.

5. Suporte ao Estudante. Esta categoria inclui um conjunto de serviços oferecidos em suporte às atividades dos estudantes tais como treinamento e assistência no uso dos recursos online. 
6. Suporte ao Corpo Docente. Os itens dessa categoria relacionam algumas atividades de assistência e suporte fornecidos por outros membros mais experientes ou por terceiros.

7. Avaliação e auditoria. Os itens nessa categoria são políticas e procedimentos que definem como as instituições devem avaliar a qualidade de seus cursos.

\subsection{A norma NBR ISO/IEC 12207 aplicada a EAD}

$\mathrm{Na}$ década de 90 houve uma grande preocupação com a modelagem e melhorias no processo de software. Para Campos [5], a qualidade do software educacional é uma questão que diz respeito aos pesquisadores, desenvolvedores e usuários porém, os pesquisadores têm explorado pouco este tema, havendo a necessidade de instanciar e desenvolver modelos e padrões de qualidade de software para o domínio educacional, tanto para o processo quanto para o produto, que contemplem as novas tecnologias e os novos requisitos educacionais.

A norma NBR ISO/IEC 12207 - Tecnologia de Informação - Processo de Ciclo de Vida de Software, provê uma infra-estrutura (framework) para o ciclo de vida do software [12]. Esta infra-estrutura consiste de processos, atividade e tarefas para a aquisição, fornecimento, projeto, desenvolvimento, operação e manutenção do software. A norma estabelece uma arquitetura de alto nível do ciclo de vida do software, estabelecida através de um conjunto de 17 processos agrupados em três classes:

1. Processos Fundamentais. É o principal conjunto de processos e forma a base do ciclo de vida de um projeto de software, indo da concepção até a sua retirada do mercado. Atendem ao início, à contratação entre o adquirente e o fornecedor e à execução do desenvolvimento, da operação ou da manutenção de produtos de software durante o ciclo de vida do software.

2. Processos de Apoio. São processos que servem de apoio às atividades e tarefas de outros processos contribuindo para sua realização. Um processo de apoio pode ser referenciado por qualquer processo (mesmo por um processo de apoio). Os processos desta classe auxiliam para o sucesso e a qualidade do projeto de software.

3. Processos Organizacionais. Uma organização emprega um processo organizacional para executar funções de nível organizacional ou mesmo corporativo que tenham alguma relação com o projeto de desenvolvimento de software.

Nesta norma, cada processo é dividido em um conjunto de atividades e cada atividade do processo é divida em um conjunto de tarefas. Uma tarefa representa um conjunto de ações atômicas elementares.

\section{Um Modelo Proposto: EduQNet}

O desenvolvimento da EAD que, do ponto de vista da tecnologia e dos processos empregados, seja confiável e de qualidade, é um verdadeiro desafio para as instituições de ensino. $\mathrm{O}$ enorme número de alunos potenciais, a complexidade da tecnologia envolvida e os novos papéis desempenhados pelo corpo docente levam as instituições tradicionais a ter um sem número de problemas quando migram ou expandem suas atividades para esta nova modalidade. 
As dificuldades enfrentadas por estas instituições são relacionadas tanto às novas abordagens pedagógicas e didáticas necessárias para a modalidade de ensino a distância, quanto à adoção de novas tecnologias para mediar as relações entre alunos, professores e instituição. Soma-se a estas dificuldades a necessidade de um novo modelo, capaz de orientar na correta elaboração dos processos de elaboração, operação, manutenção e aprimoramento das atividades relacionadas aos cursos. De fato, a qualidade na tecnologia envolvida no ensino a distância pode ser tratada de duas perspectivas, uma relacionada a aspectos pedagógicos tais como: qualidade do processo educativo, qualidade da abordagem pedagógica e didática, qualidade do programa instrucional, qualidade do corpo docente. Outra relacionada a aspectos tecnológicos tais como: qualidade nas atividades mediadas pela tecnologia; qualidade do uso da tecnologia e qualidade da tecnologia em si.

Diversas organizações internacionais têm contribuído para a padronização da tecnologia de educação a distância mediada pela Internet. $\mathrm{O}$ objetivo principal desta padronização tem sido facilitar e automatizar a busca, avaliação, aquisição e uso de recursos de aprendizagem em um ambiente Web. Neste intuito, o comitê LTSC (Learning Technologies Standardization Committee) da IEEE e a ISO/IEC, através do comitê SC36 (Standards Committee for Learning Technologies), têm sido os responsáveis por concentrar as propostas de padronização oriundas das diversas instituições e projetos de educação a distância [11,24].

Embora este tipo de padronização seja fundamental para incrementar a intercomunicação entre cursos, aumentando a possibilidade de reuso e, portanto diminuindo o trabalho repetitivo da criação e sistematização de conteúdos instrucionais, ela não fornece caminhos para a elaboração de planos para atividades intrínsecas relativas ao uso da tecnologia em cursos a distância. A partir das recomendações, guias e princípios apresentados anteriormente, foi elaborado um estudo procurando a sistematização destes conhecimentos com o objetivo de definir um modelo abrangente que garanta a qualidade dos processos que tratam da tecnologia envolvida no ensino a distância mediado pela Internet. Este modelo foi chamado de Modelo de Educação com Qualidade Mediada pela Internet - EduQNet.

O EduQNet foi definido a partir de um mapeamento dos indicadores de qualidade de EAD. Foram considerados neste mapeamento o guia de qualidade da HRDC [1], os indicadores de qualidade do MEC/SED [16] e as referências de qualidade do IHEP [22]. O guia de qualidade do C-RAC - Council of Regional Accrediting Commissions [27, 28] não foi considerado neste mapeamento uma vez que seu conteúdo foi fortemente influenciado pelas referências de qualidade do IHEP [10].

O trabalho de William F. Massy [15], que sugere o uso experimental do CMM para avaliar a penetração do trabalho de qualidade educacional nas instituições de ensino a distância, foi a inspiração para estender este mapeamento entre modelos de qualidade de EAD para modelos de qualidade de processos de desenvolvimento de software. No EduQNet foi utilizado como referência o modelo NBR ISO/IEC 12207 [12], "Tecnologia da informação processo de ciclo de vida de software" como referência para o mapeamento dos modelos de qualidade de EAD. 


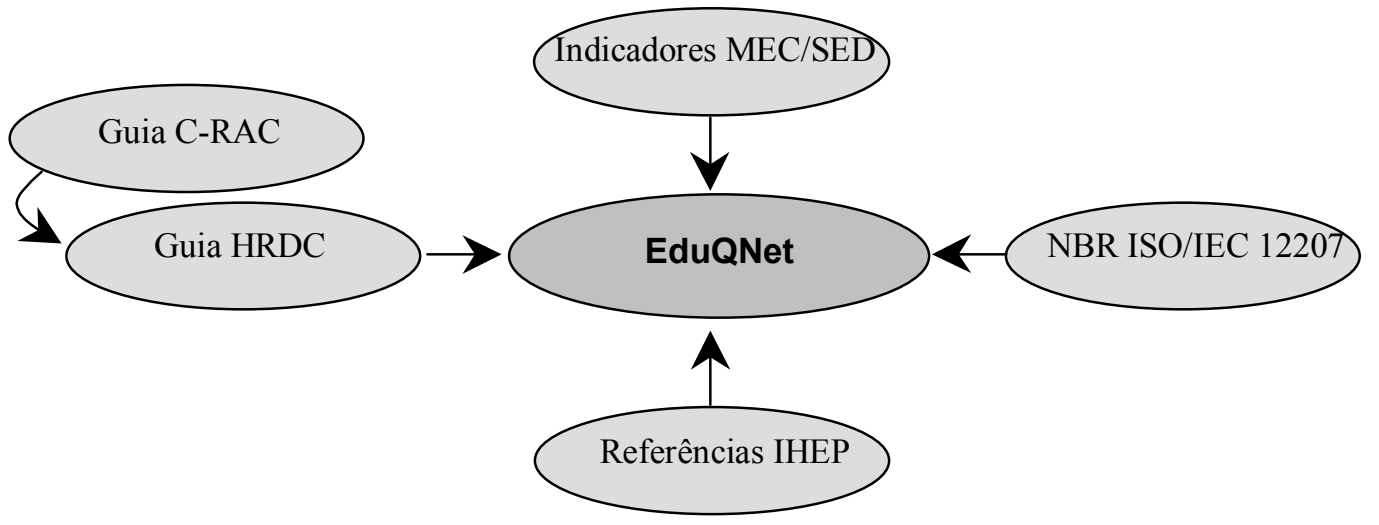

Figura 1. Os modelos que influenciaram o EduQNet

\subsection{As atividades do modelo}

O EduQNet está organizado em 14 atividades principais. Cada atividade indica uma série de sub-atividades relacionadas com o seu cumprimento.

1. Aquisição de produtos e serviços de terceiros.

Na norma NBR ISO/IEC 12207 [12], o processo 5.1 define as atividades do adquirente e é iniciado com a definição da necessidade de adquirir um sistema, um produto ou um serviço software. Segundo Campos [6], "Decidir pela compra de um determinado produto não é tarefa simples. O sucesso de um software num determinado ambiente não garante $o$ seu sucesso em outro contexto". Para garantir esse "sucesso", é necessário definir claramente quais os caminhos para aquisição destes produtos e serviços.

2. Admissão de alunos

Todas as recomendações de EAD analisadas mostram grande preocupação com esta atividade. Aqui são incluídos todos os cuidados que devem ser tomados para que o aluno tenha pleno acesso a dados sobre o curso, pré-requisitos necessários e desejáveis, infraestrutura necessária, etc. O Guia IHEP sugere que antes de iniciar um programa on-line, os estudantes devem ser aconselhados sobre o programa, incluindo requisitos para inscrição, taxas, formas de pagamento, livros e fornecedores, requisitos técnicos e de proteção, e serviços de suporte ao aluno. O MEC/SED [16] sugere a necessidade de um edital com informações sobre o cursos de graduação a distância. Já o modelo da HRDC sugere que o processo de admissão de alunos deve ser claramente definido e documentado e que devem ser fornecidas informações de forma padronizada, relevante, clara, completa e devidamente documentada.

3. Desenvolvimento do curso

Na norma NBR ISO/IEC 12207 [12] o item 5.3 define as atividades do desenvolvedor. As recomendações analisadas não mostram caminhos claros quanto ao desenvolvimento do curso a distância entretanto, apresentam indicações de aspectos que devem ser levados em consideração nesta atividade. Os indicadores do MEC/SED sugerem no item 2 que a identidade da educação a distância deve ser levada em consideração no "Desenho do projeto" do curso a distância [16]. As referências do IHEP indicam a necessidade de se prever no projeto alguns recursos tais como uma biblioteca virtual [22]. O modelo da 
HRDC apresenta uma forte preocupação com o conteúdo do currículo indicando que ele deve ser "digno de crédito, relevante, atualizado, documentado e apropriado aos objetivos". Acrescenta ainda que o conteúdo deve apresentar características modulares e ao mesmo tempo integrado para permitir uma ampla visão sobre o todo.

\section{Operação do curso}

Este processo define as atividades relativas à operação do curso por parte dos alunos e professores. São aquelas atividades executadas no dia a dia por professores, alunos e corpo técnico de suporte. As recomendações analisadas apresentam uma série de diretrizes que têm que ser levadas em conta nestas atividades. O MEC/SED sugere no item 4 a necessidade de intensa comunicação e interatividade entre professor e aluno. $\mathrm{O}$ modelo da HRDC indica a necessidade de processos e práticas relativos às facilidades de comunicação que encorajem a interação entre os alunos, dos alunos para com os professores e para com a instituição.

Outra preocupação das recomendações é quanto a forma de avaliação dos alunos. As referências de qualidade do IHEP recomendam que os estudantes sejam supridos com informações suplementares sobre o curso e seus objetivos e concepções bem como a forma como serão feitos os exames necessários para a conclusão do curso. Para Massi [15] é importante que o processo de avaliação do estudante esclareça uma série de questões tais como: (i) Que métricas e indicadores serão usados para avaliar a aprendizagem dos alunos?; (ii) Como os alunos terão acesso a estes resultados? (iii) Como serão determinados os objetivos educacionais de longo prazo? (iv) Quem será o responsável pela avaliação?

\section{Manutenção do curso}

Segundo Vieira [26], a maior dificuldade na consolidação de um programa de ensino a distância mediado pela Internet não é a criação do site em si, mas a sua manutenção, uma vez que requer uma quantidade enorme tempo e dedicação dos profissionais (normalmente, os próprios professores) engajados nesse processo.

Apesar de toda esta dificuldade, as recomendações analisadas não parecem dar muita importância a este aspecto. As poucas indicações que aparecem são de forma indireta. $\mathrm{O}$ guia do IHEP recomenda que as respostas às reivindicações e questionamentos dos alunos devem ser apresentadas de forma construtiva e rápida através de um sistema automatizado. Isto leva-nos a pensar que "defeitos" identificados por alunos devam ser corrigidos rapidamente.

\section{Documentação}

Este processo determina quais documentos devem ser controlados, as instruções para sua alteração e até critérios de segurança destes.

As únicas menções feitas a este processo estão no guia do IHEP que determina que o curso deve ter e manter documentos guia garantindo a padronização do projeto, desenvolvimento e lançamento do curso e no item 5, que os materiais institucionais devem ser revisados periodicamente para garantir o cumprimento do programa de padronização.

O Sistema de Padrões para Gestão de Informática Educativa [5], é uma proposta de um sistema de padrões inspirados nos padrões de projeto da orientação a objetos, desenvolvido para ser usado em projetos de que envolvam informática educativa. Os 
padrões propostos deste sistema são relacionados a: (i) tecnologias de hardware e software; (ii) desenvolvedores de software educacional; (iii) políticas externas à instituição escolar; (iv) políticas internas das escolas. Este sistema poderia auxiliar na definição de padrões para a documentação de projetos de EAD.

\section{Gerência de configuração}

Durante um curso é produzida uma grande quantidade de itens de informação que podem ser alterados ao longo do tempo. Para que estas alterações não gerem inconsistências elas devem ser acompanhadas. O processo de gerência de configuração é um processo que permite que esse controle seja realizado. Segundo Fiorini [8], a finalidade principal da gerência de configuração é estabelecer e manter a integridade dos produtos do projeto ao longo do seu ciclo de vida. No caso do ensino a distância mediado pela Internet, esta atividade deverá controlar entre outras coisas: o conteúdo instrucional disponibilizado para os alunos; os guias, manuais, relatórios técnicos usados como suporte ao processo de aprendizado; os materiais desenvolvidos pelos alunos ao longo do curso e que tenham sido compartilhados através do ambiente telemático; os materiais desenvolvidos pelos professores em atividades administrativas tais como atas de reuniões departamentais, currículos, projetos de extensão.

As referências de qualidade do IHEP indicam a necessidade de um plano de tecnologia documentado que inclui medidas de segurança (senha de proteção, criptografia, sistemas de cópias de segurança, etc.) para garantir a integridade e validade das informações.

8. Processo de garantia da qualidade

A abrangência desse processo inclui questões como garantia da qualidade do curso e da qualidade do processo de elaboração do curso. Todas as recomendações analisadas mostram grande preocupação com esta atividade. Nas referências de qualidade do IHEP, recomenda-se elaborar um plano de tecnologia documentado para garantir o padrão de qualidade. As recomendações do MEC/SED mostram preocupação quanto ao estabelecimento de padrões de qualidade que busquem integração com políticas, diretrizes e padrões de qualidade definidos para o ensino superior como um todo.

A qualidade em EAD pode ser abordada de muitas formas. Uma delas é estabelecer aspectos de qualidade do curso, outra é a da qualidade do processo de elaboração do curso. Há vários trabalhos que tratam da qualidade do curso sob diversos aspectos tais como: qualidade no desenvolvimento de aplicativos multimídia de treinamento [14]; padrões para avaliação da qualidade de software educacional [6]; metodologia para a avaliação da qualidade do desenvolvimento e da seleção de produtos de software educacional [4]; instrumentos de avaliação de qualidade de software educacional [9]; avaliação de sistemas de autoria hipermídia educacional [21].

9. Revisão conjunta, verificação e validação e auditoria

Segundo Rocha [25], o processo de verificação é usado para determinar se os produtos de uma atividade atendem completamente aos requisitos ou às condições impostas a eles. Por outro lado, o processo de validação é usado para determinar se os requisitos e o produto final atendem ao uso específico proposto. Já a revisão conjunta define as atividades para avaliar a situação e os produtos de uma atividade de um projeto e realizadas tanto nos níveis de gerenciamento do projeto como nos níveis técnicos. O objetivo destas três atividades é fornecer suporte técnico para as atividades de garantia da qualidade. 
Segundo as referências de qualidade do IHEP a eficiência do programa educacional deve ser avaliada através um processo que use vários métodos e aplique padrões específicos. Além disso, dados sobre inscrições, custos e usos bem sucedidos da tecnologia devem ser usados para avaliar a eficiência e os objetivos dos cursos. De forma semelhante, o modelo da HRDC propõe que o curso como um todo, incluindo os materiais e tecnologias, sejam rotineiramente avaliados e que sejam estabelecidas atividades rotineiras de revisão e avaliação do curso (conteúdo, material didático, projeto pedagógico, etc.).

Os modelos Norte Americanos tais como os padrões de referência da IHEP e o guia do CRAC foram fortemente influenciados pela necessidade de parâmetros para os processos de auditoria realizados por agências de reconhecimento ou de "acreditação" [7, 20].

\section{Processo de resolução de problemas}

O objetivo desse processo é fornecer meios que garantam a análise e a resolução de todos os problemas encontrados e a identificação das tendências de novas ocorrências. Quando um problema for detectado em uma atividade ou produto utilizado no curso, um relatório de Problema Detectado deverá ser elaborado. Este relatório deve descrever o problema encontrado e, se possível, sua causa, bem como as ações para a sua solução.

\section{Processo de gerência}

Segundo Rocha [25], há um consenso na literatura de que a gerência é um dos aspectos mais críticos dos projetos de software. O modelo da HRDC define processos e práticas de gerência dos alunos, do aprendizado, de recursos humanos e contábil. Sob a perspectiva contábil, este modelo sugere ainda que o retorno do investimento financeiro, tempo e esforço devem ser compatíveis com as expectativas. A este respeito, as recomendações do MEC/SED sugerem no item 10 que os custos de implementação e manutenção da graduação a distância sejam devidamente gerenciados.

12. Processo de infra-estrutura

A infra-estrutura destina-se tanto à assistência de professores, quanto de alunos e pessoal de apoio. A infra-estrutura pode incluir hardware, software, ferramentas, técnicas, padrões e recursos para o desenvolvimento, a operação ou a manutenção do ambiente telemático.

A maior atenção a este processo é dada pelas referências de qualidade do IHEP que sugere entre outras coisas pertinentes, que um sistema centralizado deve prover suporte para a construção e manutenção da infra-estrutura do ensino a distância. Sugere também que interação do estudante com a instituição, com os professores e com os outros estudantes, deve ser facilitada através de uma gama de possibilidades incluindo voice-mail e e-mail. As recomendações do MEC/SED tratam estas atividades como "Infra-estrutura de apoio".

\section{Processo de melhoria}

Na NBR ISO/IEC 12207 o processo de melhoria define as atividades básicas que uma organização (isto é, adquirente, fornecedor, desenvolvedor, operador, mantenedor ou o gerente de outro processo) executa para estabelecer, avaliar, medir controlar e melhorar um processo de ciclo de vida.

\section{Processo de treinamento}

Segundo Rocha [25], a aquisição, o fornecimento, o desenvolvimento, a operação ou a manutenção de produtos de software é extremamente dependente de pessoal com conhecimento e qualificação. Portanto, é essencial que o treinamento de pessoal seja 
planejado e implementado com antecedência para que o mesmo esteja disponível quando o software for adquirido, fornecido, desenvolvido, operado ou mantido.

Este processo define as atividades para oferecer e manter professores, pessoal técnico e alunos treinados no uso da tecnologia. Pelas referências de qualidade do IHEP, os professores devem ser assistidos e assessorados na sua transição do ensino presencial para o ensino online, para isso, devem ser providos com recursos escritos e treinamentos continuamente (item 20).

\section{Conclusões}

A definição de um processo de qualidade é uma atividade extremamente criativa e demanda um enorme esforço para a definição da arquitetura a ser utilizada. Neste aspecto o uso de um modelo de qualidade já definido como o NBR ISO/IEC 12207 representou um grande atalho, uma vez que a organização do modelo e sua arquitetura puderam ser amplamente aproveitados.

A definição do EduQNet abre algumas possibilidades de trabalhos futuros. Um deles é estender e completar o processo de instanciação do EduQNet no âmbito do NE@AD, definindo todas as atividades pertinentes. Outro trabalho futuro é o desenvolvimento de uma ferramenta automática para a elaboração dos processos dos cursos e a definição de um ambiente telemático organizado a partir das atividades definidas pelo EduQNet..

Há também a possibilidade de incorporar ao EduQNet as padronizações da tecnologia proposta para facilitar e automatizar a busca, avaliação, aquisição e uso de recursos de aprendizagem em ambiente WEB, propostas pelo IEEE/LTSC (Learning Technologies Standardization Committee) e pela ISO/IEC $[11,24]$.

Um trabalho necessário é estabelecer a real relação entre qualidade do processo de educação a distância e a aprendizagem adquirida pelo aluno. A relevância deste trabalho estaria em relacionar o quanto a organização sistemática do processo em EAD influencia o desempenho do aluno do ponto de vista de sua aprendizagem.

A interdisciplinaridade deste trabalho nos fez ter contato com profissionais de diversas áreas, todos imbuídos da responsabilidade de criar um processo educacional mais acessível, democrático e de qualidade, independentemente da abordagem presencial ou a distância. Afinal; "[...] com mais ou menos presença em uma sala de aula, o que importa para o cidadão e para a sociedade brasileira é ter uma formação pautada em inquestionável padrão de qualidade." [16].

\section{Referências}

[1] BARKER, K., 1999, "Quality guidelines for technology assisted distance education”. FuturEd. www.furured.com.

[2] BELLONI, M.L., 2001, "Educação a distância". Editora Autores Associados. (Coleção educação contemporânea). 2a Edição. Campinas - SP.

[3] CAMPOS, F.C.A., CAMPOS, G.H.B., 1997, "Design instrucional, novas tecnologias e desenvolvimento de software educacional”. In: VIII SBIE, pp.289-311.

[4] CAMPOS, G.H.B., 1994, "Metodologia para avaliação da qualidade de software educacional. Diretrizes para desenvolvedores e usuários”. Tese de D.Sc. COPPE. 
[5] CAMPOS, F.C.A., 1999, "Informática Educativa: Características e Padrões para Projetos". Tese de D.Sc. COPPE.

[6] CAMPOS, F.C.A., ROCHA, A.R.C., CAMPOS, G.H.B., 1999, "Qualidade de Software Educacional: Padrões para Avaliação". In: X SBIE, pp41-48.

[7] EATON, J.S., 2002, "Maintaining the delicate balance: distance learning, higher education accreditation, and the politics of self-regulation", ACE - American Council on Education, Washington, DC.

[8] FIORINI, Soeli T., STAA, Arndt, BAPTISTA, Renan M., 1998, "Engenharia de software com CMM". Rio de Janeiro: Brasport.

[9] GLADCHEFF, A.P., SNACHES, R., SILVA, D.M., 2001, "Um instrumento de avaliação de qualidade de software educacional: como elaborá-lo". In: WQS Workshop de Qualidade de Software, pp.100-113.

[10] HOPE, A., 2001, "Quality Assurance”. In: GLEN, M. F. (Editor), "The changing faces of virtual education", The Commonwealth of Learning Publisher, Vancouver - Canada, Chapter 7, pp.125-140.

[11] ISO/IEC JTC1 SC36 http//jtcl.sc36.org.

[12] NBR ISO/IEC 12207:1995, 1997, "Tecnologia da informação - processo de ciclo de vida de software", ABNT.

[13] KAWASAKI, E.I., CARVALHO, J., FERNANDES, C.T., 2001, "Uma proposta para aprofundar $\mathrm{o}$ aprendizado através da cooperação em ambientes virtuais de aprendizagem", In: XII SBIE, pp.161-167.

[14] KOZAK, D.V., BORTOLOZZI, F., EBERSPÃCHER, F., ELEUTERIO, M.A., 1998, "Metodologia, gerenciamento e qualidade no desenvolvimento de aplicativos multimídia de treinamento". In: IX SBIE, pp.380-392.

[15] MASSI, W.F., 2001, "Applying business quality principles to academic audit: Hong Kong's second-round TLQPR", In: $6^{\text {th }}$ Biennial Conference of the International Network for Quality Assurance Agencies in Higher Education, Bangalore - India, March 2001.

[16] MEC/SED Ministério da Educação / Secretaria de Ensino a Distância, 2002, "Indicadores de qualidade para cursos de graduação a distância", www.mec.gov.br.

[17] MENEZES, C. S., CURY, D., TAVARE, O.L., CAMPOS, G.H.B., CASTRO, A.N., 2000, "An Architecture of an Environment for Cooperative Learning (AmCorA)". ICECE - São Paulo, Brasil.

[18] NEAAD, 2000, "Projeto de implantação do curso de licenciatura plena em educação básica séries iniciais - $1^{\mathrm{a}}$ a $4^{\mathrm{a}}$ séries". NE@AD - Núcleo de Educação Aberta e a Distância - UFES, Agosto.

[19] NUNES, I.B., 1993, "Noções de educação a distância". In: Revista Educação a Distância. Vols. 3, 4 e 5. Dezembro/1993 a Abril/1994. Brasília - INED.

[20] OPE - Office of Postsecondary Education, 2002, "Accreditation in the U.S.". www.ed.gov/offices/OPE.

[21] PAIVA, D.M.B., NUNES, M.G.V., FORTES, R.P.M., 2001, "Qualidade de produto de software: Avaliação prática de um sistema de autoria hipermídia educacional”. In: WQS 2001, p114-122.

[22] PHIPPS, R., MERISOTIS, J., 2000, “Quality on the line - benchmarks for success in Internet-based distance education”, IHEP, Washington, DC. www.ihep.com/quality.pdf. 
[23] PRETI, O., 1998, "Educação a distância e globalização". In: Revista Brasileira de Estudos Pedagógicos, Brasília, Janeiro/Abril, pp.19-30.

[24] RIFÓN, L.A., NISTAL, M.L., IGLESIAS, M.J., 2001, “A component model for standardized web-based education". In: ACM, p86-95.

[25] ROCHA, A.R.C.R, MALDONADO, J.C., WEBER, K.C., 2001,“ Qualidade de software: teoria e prática". São Paulo: Prentice Hall.

[26] VIEIRA, E.A., ANGULO, E.U., OMAR, N., 2001, "Um modelo de apoio ao ensino em universidades particulares". In: XII SBIE, pp.110-117.

[27] WICHE - Western Interstate Commission for Higher Education, "Statement of the Regional Accrediting Commissions on the Evaluation of Electronically Offered Degree and Certificate Programs", www.wiche.edu/telecom/resources/publications.

[28] WICHE - Western Interstate Commission for Higher Education, "Guidelines for the Evaluation of Electronically Offered Degree and Certificate Programs", www.wiche.edu/telecom/resources/publications. 